\title{
Advanced Abdominal Ectopic Pregnancy: A Case Report
}

\author{
Okechukwu B. Anozie1*, Chidi U. O. Esike1, Justus N. Eze1, Emeka Onwe Oga², \\ Mathew Igwe Nwali', Kennedy 0. Otti ${ }^{1}$ \\ ${ }^{1}$ Department of Obstetrics and Gynaecology, Federal Teaching Hospital Abakaliki, Ebonyi State, Nigeria \\ ${ }^{2}$ Department of Paediatrics, Federal Teaching Hospital Abakaliki, Ebonyi State, Nigeria \\ Email: "okeyanoziey2k@yahoo.com
}

Received 2 April 2016; accepted 9 May 2016; published 12 May 2016

Copyright (C) 2016 by authors and Scientific Research Publishing Inc.

This work is licensed under the Creative Commons Attribution International License (CC BY). http://creativecommons.org/licenses/by/4.0/

(c) (i) Open Access

\section{Abstract}

A 35-year-old unbooked gravida 6 para 5+0 woman with 4 living children, who was unsure of her last menstrual period but she adjudged her index pregnancy to be term. She presented to the emergency unit with six months history of progressive weight loss, difficulty in breathing and abdominal pain that suddenly got worse about two days prior to presentation after an attempted external cephalic version by a traditional birth attendant. Ultrasound diagnosed abdominal pregnancy. An emergency laparotomy revealed collapsed fetal membranes with a rent of about 10 centimeters in diameter on the right and straw-colored amniotic fluid of about 2 litres in peritoneal cavity. A live male fetus was delivered with birth weight of 2.9 kilograms. The umbilical cord was cut and tied short close to the placenta which was left in situ and methotrexate was given. Post operative condition was satisfactory and patient had a brisk recovery. She was adequately counseled and discharged home on the $12^{\text {th }}$ day after surgery and followed up subsequently.

\section{Keywords}

Abdominal Pregnancy, Ectopic, Live Fetus, Methotrxate, Ultrasound and Placenta

\section{Introduction}

Abdominal pregnancy is a rare form of ectopic gestation where the gestational sac implants in any structure within the peritoneal cavity. It constitutes about $1 \%$ of ectopic gestation [1]. Incidence of abdominal pregnancy ranged from 1 in 10,000 to 1 in 30,000 pregnancies [1]-[9]. Abdominal pregnancy is associated with increased risk of early fetal wastage, fetal malformations, perinatal morbidity and mortality as well as maternal morbidity

${ }^{*}$ Corresponding author.

How to cite this paper: Anozie, O.B., Esike, C.U.O., Eze, J.N., Oga, E.O., Nwali, M.I. and Otti, K.O. (2016) Advanced Abdominal Ectopic Pregnancy: A Case Report. Open Journal of Obstetrics and Gynecology, 6, 360-364.

http://dx.doi.org/10.4236/ojog.2016.66046 
and mortality [2]. We report a case of advanced abdominal pregnancy in an unbooked multipara who had successful laparotomy with delivery of a live fetus.

\section{Case Report}

The patient was a 35 year old unbooked gravida 6 para $5^{+0}$ with 4 living children, a subsistence farmer who was not sure of her last menstrual period but adjudged her pregnancy to be term. She presented to the emergency unit with six months history of abdominal pain that suddenly got worse about two days prior to presentation and progressive weight loss as well as difficulty in breathing. Index pregnancy was different from her previous experiences. The pain described as constant in the last 48 hours prior to presentation had become particularly intense that the patient could not sleep at night.

She had been visiting traditional birth attendants who prescribed several herbal medicines and attempted "turning the baby" (external cephalic version) without relief of her symptoms, hence her presentation to the general outpatient department of our centre. A diagnosis of ovarian tumor coexisting with pregnancy was made and she was subsequently referred to obstetric emergency department.

The patient had five confinements between 2003 and 2012. Pregnancies, labour, and peuperium were uneventful. The $4^{\text {th }}$ child died at six months of age from febrile illness at home. She did not take alcohol or tobacco in any form.

She was a young woman but chronically ill-looking, pale, afebrile, anicteric dehydrated, with no demonstrable pitting pedal edema but in moderate painful distress. Her pulse rate was 100 beats per minute of moderate volume and regular. Her blood pressure was $120 / 80 \mathrm{mmHg}$.

The abdomen was distended with generalized tenderness, so the symphysio fundal height could not be measured. Abdominal palpation was difficult because of the generalized tenderness.

Vaginal examination showed centrally located parous, firm, uneffaced cervix, and uterus appeared mobile from side to side independently of the fetus.

\section{Ultrasound Findings}

A bulky anteverted uterus that measured $140 \mathrm{~mm}$ by $81 \mathrm{~mm}$ in longitudinal and anterior-posterior diameters respectively. Endometrial strip was $12 \mathrm{~mm}$ thick. Uterine vessels were enlarged. Intraperitoneal viable singleton fetus with the head to the maternal left was noted. The placenta was attached to the mesentery. Liquor volume was adequate. Fetal heart rate was 145 beats/minute. Biometry: femur length $=67 \mathrm{~mm}$, Biparietal diameter $=88$ $\mathrm{mm}$. Estimated gestational age $=35$ weeks.

Her packed cell volume was $26 \%$ and her blood group was O rhesus D positive. Retroviral screening was non reactive. Her urinalysis was normal.

A diagnosis of advanced abdominal pregnancy was made. The patient and her spouse were counseled on the findings and need for emergency laparotomy.

The surgery was done under general anaesthesia. A midline incision which was extended above the umbilicus was made. The peritoneal cavity was opened. The findings were abdominal pregnancy covered in collapsed amniotic sac with a rent of about 10 centimtres in diameter on the right. Massive straw-coloured amniotic fluid about 2 litres in peritoneal cavity was noted. A live male fetus with distended abdomen and Apgar scores of 4 and 0 in the first and fifth minutes respectively was delivered with birth weight of 2.9 kilograms. The placenta was attached to the transverse colon above and extended to the fundus of uterus below. This structure obscured the fundus of the uterus and its adnexae. The umbilical cord was cut and tied short close to the placenta which was left in situ. A drain was inserted and connected to urine bag. Estimated blood loss was 1 litre.

She received I litre of normal saline alternated with 5\% dextrose water 8 hourly for 72 hours. She also received $30 \mathrm{mg}$ of pentazocine 4 hourly for 24 hours, $1 \mathrm{~g}$ of ceftriaxone 12 hourly and $500 \mathrm{mg}$ of metronidazole 8 hourly for 72 hours. She received two units of blood intraoperatively and two more within the post operative period. She was commenced on oral sips on the second post-operation day following return of bowel sounds. On the third postoperative day she was started on oral haematinics, cefpodoxime $200 \mathrm{mg}$ twice daily and flagyl 400 mg trice daily for one week. The abdominal drain was removed on the third day following 24 hour collection of less than $15 \mathrm{ml}$ of serosanguinous fluid. The packed cell volume on the $7^{\text {th }}$ postoperative day was $25 \%$; hence alternate stitches on the abdominal incision wound were removed. She was subsequently transfused a unit of blood on the $7^{\text {th }}$ postoperative day. On the $8^{\text {th }}$ post-operative day the remaining stitches were removed and intra- 
muscular methrotrexate $50 \mathrm{mg}$ was given to her. Her packed cell volume on the $10^{\text {th }}$ day post-operation was $27 \%$. The liver functions tests, serum electrolytes, urea and creatinine remained within normal limits. Bedside clotting time was 3 minutes. On the $12^{\text {th }}$ post operative day the patient was up and about with stable vital signs and packed cell volume of $27 \%$. She was then discharged home. She was adequately counseled and given two weeks follow up appointment.

The problems the patient had were again explained to her and to her husband. The long course it would take for resorption of the products of conception left in situ, the risk of bleeding intra-abdominally, sepsis, coagulopathy, intestinal obstruction, anaemia and possible early symptoms of these problems for which she would return to the hospital were explained to her. The social welfare unit was invited to trace the patient to her home and to obtain contacts of informed relatives that lived close to her who would collaborate with us to ensure she kept her appointments. The patient was seen two weeks after discharge in the clinic, and had no obvious complaints and her pack cell volume was $29 \%$. Her clinical examination was normal, and she was counseled on family planning and discharged to the family planning unit (Figures 1-4).

\section{Discussion}

Abdominal pregnancy is a rare finding constituting about $1 \%-2 \%$ of ectopic pregnancies [1]. It is said to be commoner with primigravidae, blacks and women of low socioeconomic group. Due to misdiagnosis and in-

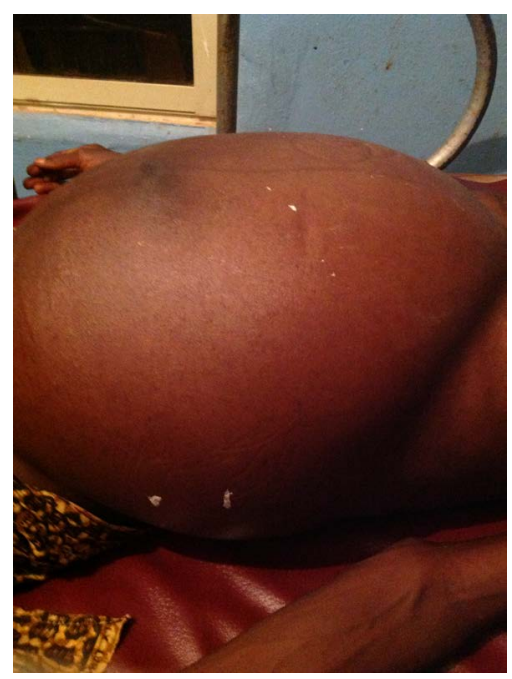

Figure 1. Advanced abdominal pregnancy on presentation at accident and emergency.
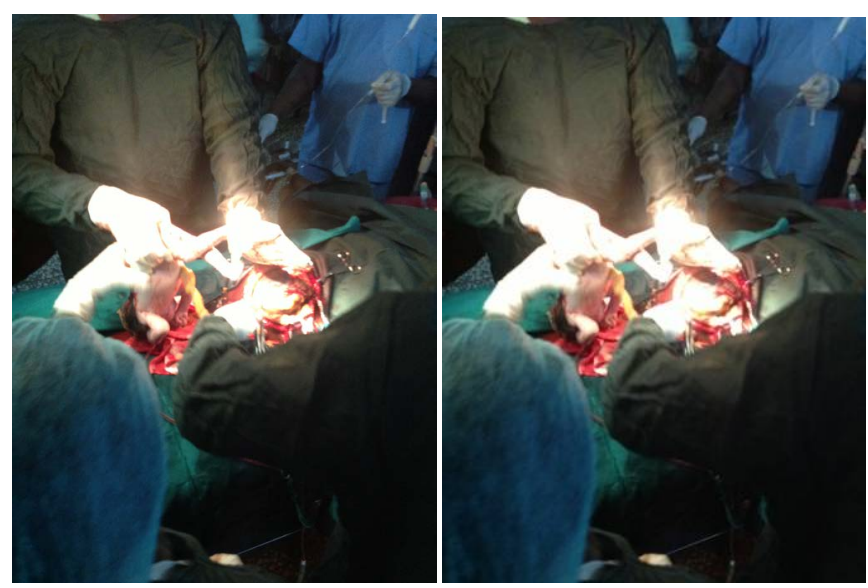

Figure 2. Entry into the peritoneal cavity showing the fetal membranes. 


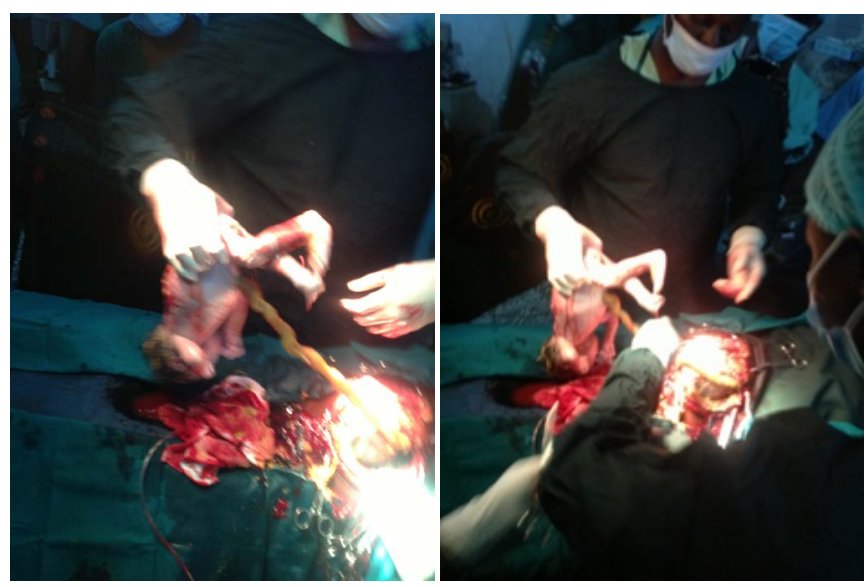

Figure 3. Delivery of a live baby during laparotomy in advanced abdominal pregnancy.

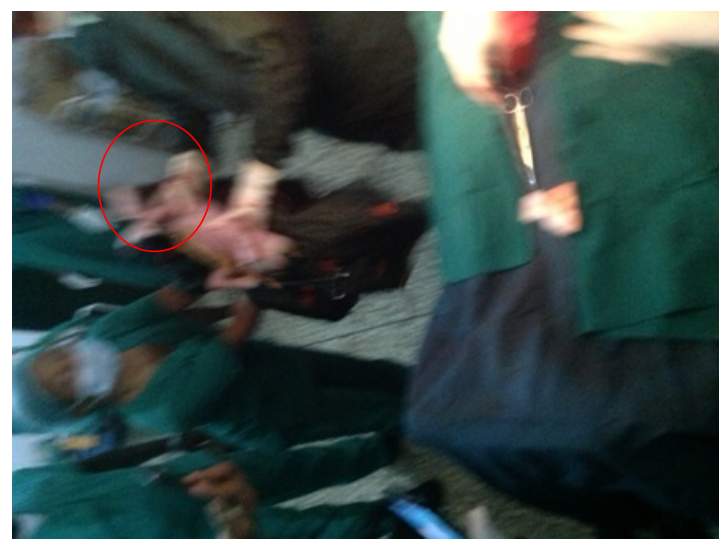

Figure 4. Delivered baby with talipes deformity and distended abdomen.

appropriate treatment, complications in the natural course of the condition and late presentation morbidity and mortality for the parturients and babies are significantly high [2]. Our patient who is of low socioeconomic background presented late after inappropriate intervention by unskilled personnel who misdiagnosed her and attempted external cephalic version which might contributed to her acute condition. Even in the best hands, except there is high index of suspicion, misdiagnosis is common.

Abdominal pregnancy is said to be advanced when the fetus has survived beyond 20 weeks or showing signs of having lived above 20 weeks [3]. It can be primary or secondary. Primary abdominal pregnancy which is rarer, occurs when the pregnancy ab initio implanted in the peritoneal cavity. In secondary abdominal pregnancy, the zygote was initially implanted in the Fallopian tube, or uterus but following tubal abortion or rupture of the tube or uterus, the embryo now establishes implantation in the peritoneal structures and survive. Diagnosis of primary abdominal pregnancy at laparotomy is made by Studdaford criteria. These include findings of normal bilateral fallopian tubes and ovaries, absence of uteroperitoneal fistula and the presence of a pregnancy related to the peritoneal surface exclusively. Our patient most likely had secondary abdominal pregnancy as the criteria for primary abdominal pregnancy were not consistent with the finding in this case. The common presentation of advanced abdominal pregnancy as was seen in our case include persistent abdominal pain, wasting, abnormal lie, painful perception of fetal movement and less frequently, vaginal bleeding. It may be an incidental finding on ultrasound for other indications particularly in early gestations.

The treatment of abdominal pregnancy is laparotomy. The timing depends on the gestational age and presence or absence of concomitant complications. Generally, abdominal pregnancies discovered before 24 weeks of gestation are removed following laparotomy. In the absence of complications and under direct medical supervi- 
sion, those discovered after 24 weeks may be monitored to viability and then delivered by laparotomy. In either scenario, the placenta will be removed if it appears to be easy to do so. Difficult or piecemeal removal can lead to severe haemorrhage in which case it is preferable to leave the placenta in situ with the umbilical cord tied and cut short as was done in our case.

While the role of methotrexate in hastening resorption of the placenta and membranes left in situ is doubted by few and may actually increase the volume of necrotic tissue to be absorbed and therefore encouraging sepsis, majority give the drug adjuvantly with the hope of quickening the process of resorption. To limit the systemic side effect of methotrexate, a single intraumblical vein injection is given at laparotomy [5] [6]. The quantity and duration of methetrexate have not been established. Our patient got a dose of methotrexate seven days post partum. Prior to her discharge, the serum $\beta$ hCG was 76 iu and her clotting time was 3minutes.

A drain was left in place due to significant oozing of blood at the time of laparotomy but was promptly removed when effluents significantly reduced on the third post operative day. It is not encouraged to leave a drain following laparotomy for abdominal pregnancy because of fear of introducing infection [7].

The fetus suffered early neonatal death. Abdominal pregnancy is associated with high perinatal mortality [8]. This is due to high rate of fetal anomalies like in our patient's baby that had distended abdomen with talipes deformities and development of complications such as prolonged pregnancy and placental abruption. Also problem of illiteracy, poverty, poor health seeking behavior, late presentation and the activities of non-skilled personnel might have contributed to the severe asphyxia at birth and early neonatal death. The baby's abdomen was distended at birth. The parent did not consent to autopsy because of cultural reasons.

\section{Conclusion}

In conclusion, abdominal pregnancy is associated with misdiagnosis, mismanagement, high perinatal and maternal morbidity and mortality. Early intervention in tertiary institution, optimum management of the placenta and adequate postoperative care are keys to successful outcome.

\section{References}

[1] Nwobodo, E.I. (2004) Abdominal Pregnancy. A Case Report. Annals of African Medicine, 3, 194-196.

[2] Ikechebelu, J.I., Onwusulu, D.N. and Chukwugbo, C.N. (2005) Term Abdominal Pregnancy Misdiagnosed as Abruptio Placentae. Nigerian Journal of Clinical Practice, 8, 43-45.

[3] Nkusu Nunyalulendho, D. and Einterz, E.M. (2008) Advanced Abdominal Pregnancy: Case Report and Review of 163 Cases Reported since 1946. Rural Remote Health, 8, 1087.

[4] Masukume, G., et al. (2013) Full-Term Abdominal Extrauterine Pregnancy Complicated by Post-Operative Ascites with Successful Outcome: A Case Report. Journal of Medical Case Reports, 7, 10. http://dx.doi.org/10.1186/1752-1947-7-10

[5] Jurkovic, D. (2007) Ectopic Pregnancy. In: Edmonds, D.K., Ed., Dewhurst's Textbook of Obstetrics and Gynaecology for Postgraduates, 8th Edition, Blackwell Publishing, London, 76-87.

[6] Cardosi, R.J., Nackley, A.C., Londono, J. and Hoffman, M.S. (2002) Embolization for Advanced Abdominal Pregnancy with a Retained Placenta. A Case Report. The Journal of Reproductive Medicine, 47, 861-863.

[7] King, M. and Bewes, P.C. (1999) The Surgery of Pregnancy. In: King, M., Bewes, P.C., Cairns, J. and Thornton, J., Eds., Primary Surgery: Volume One; Non-Trauma, Oxford University Press, Jena.

[8] Ayinde, O.A., Aimakhu, C.O., Adeyanju, O.A. and Omigbodun, A.O. (2005) Abdominal Pregnancy at the University College Hospital, Ibadan: A Ten-Year Review. African Journal of Reproductive Health, 9, 123-127. http://dx.doi.org/10.2307/3583166

[9] Baffoe, P., Fofie, C. and Gandau, B.N. (2011) Term Abdominal Pregnancy with Healthy Newborn: A Case Report. Ghana Medical Journal, 45, 81-83. http://dx.doi.org/10.4314/gmj.v45i2.68933 